\title{
Using Expressive \\ Writing to \\ Improve \\ Horticultural \\ Education
}

\author{
Doug S. Foulk and \\ Emily E. Hoover
}

Additional index words. education, expressive, writing-to-learn

Summary. Horticulture students in an entry-level course (plant propagation) and an upper-level course (small fruit crop production) were assigned brief lecture-based writing tasks at the end of each class period. For the first 5 minutes of each subsequent class period, students divided into small groups to discuss their responses to the previous day $s$ task and to generate questions related to the task topic. The class then reconvened as a whole for a question-and-answer session before the lecture was resumed. Students collected their task responses in a workbook that they turned in for experimental evaluation at the end of the quarter. When compared to previous and concurrent sections of the same courses, students engaging in the writing tasks more frequently posed questions in class, posed questions of increased complexity, and demonstrated improved ability to perform well on complex exam questions requiring integration and synthesis of information.

S cientists engaged in educational research have touted the value of expressive writing to the educational process (e.g., Berghage and Lownds, 1991; Couch, 1991; Fulwiler, 1986, 1987); yet, this type of composition is still under-used in horticultural science courses. Within our discipline, virtually all required student writing is still what Britton classified as transactional-i.e., writing that informs, instructs and generally communicates to others (see Fulwiler, 1986). Examples of transactional writing in-

Department of Horticultural Science, University of Minnesota, St. Paul, MN 55108. 
elude laboratory reports, literature reviews, and $8 \%$ answer or essay exams.

When students engage in transactional writing, the act of applying pen to paper is less a learning process than it is a formal demonstration of previous learning. Further, the act of transactional writing normally involves an editing process that Goldberg (1986) terms the internal censor. The internal censor originates from the situation in which the written product is for a potentially impersonal and/or unsympathetic audience; in response, writers restrict their thought processes to include only that information that does not involve risk-less open to challenge

Expressive writing, on the other hand, is not ruled by the internal censor. Expressive writing is truly thinking on paper; it encourages cognitive processing and, in so doing, enhances learning. The resulting written product contains thoughts, feelings, and insights intended for the author s own use or for a trusted personal audience. Bemiller (1987) characterizes expressive writing as informal, personal, self-expressive, talky, tentative, speculative, exploratory, digressive, and searching. The main idea is for the student writer to engage her/himself in the course s concepts by committing thought to visible, written form.

One point needs to be absolutely clear: expressive writing is not creative writing. It is the thought process made visible. Couch (1991) asserts that students should engage in more expressive writing, noting that even a 5-min session each class period:

-allows students to see to what extent they have mastered the material that has been presented;

- lets instructors see any points of confusion students may have concerning lectures, projects, or reading materials; and

-encourages feedback between individual students and the instructor.

The feedback that occurs with this method, according to Couch, is vital in demonstrating to students that writing can be an act of communication valuable to the learning process, not just busywork. An enhanced level of communication is obviously beneficial both to the instructor and student.

Prior to our study, expressive writing had not been used in the Univ. of Minnesota Dept. of Horticultural Sci- ence curriculum. Among our faculty members, the expectation has been that students should learn through lecture attendance, textbook study, and laboratory participation-just as they themselves did. This expectation is based on a common belief in what Knoblauch and Brannon (1983) have labeled a faulty paradigm concerning the nature of knowledge and learning:

Instructors both in English and other fields often assume that knowledge is a stable and bounded artifact, a collection of information, a set of facts and ideas to be delivered to students though lecturesand course readings. The goal of instruction is to cover a subject by enumerating. its relevant data. The teacher as knower recalls the body of facts and conveys it to students, Learners, who passively receive it and store it, perhaps for later retrieval in term papers or examinations. Learning means receiving information; knowing is the condition of having retained it, which can be measured by students ability to report it in writing at a teacher s discretion. Teaching means turning learners into knowers by passing on to them the substance of knowledge.

The inadequacy of the above paradigm is exposed by the realization that learning, according to Knoblauch and Brannon, is the process of an individual mind making meaning from the materials of its experience. They suggest that writing enables new knowledge because the act of composing always involves searching for relationships between new concepts and previous learning. Instructors should teach, they advise, by creating incentives and contexts for learning, not a reporting of data.

Johnson et al. (1991) also described the need for a shift in instructional paradigms. The old paradigm, . . to transfer the faculty s knowledge to a passive student so that faculty can classify and sort students in a normreferenced, competitive way, has been carried forward by sheer momentum, even though we know this paradigm has no basis in fact. The authors propose that a more accurate paradigm involves cooperative learning in which instructors ...help students construct their knowledge in an active way while working cooperatively with classmates so that students talents and competencies are developed. As a unique active learning device, expressive writing fits effectively into such an approach.

Despite such findings, assigned student writing in horticulture curricula has fallen normally into one of two categories, both transactional: the formal term paper or literature review in which students report on what they have read; and the lab report, a descriptive account of a process or experiment. Because we agree with Knoblauch and Brannon in their assertion that knowledge implies the making of connections, not an inert body of information, it is clear to us that another teaching approach-one involving a more accurate paradigm of learning as an active, joint venture between instructor and studentshould be introduced into our curriculum. If we accept the hypothesis that expressive writing enhances the learning process significantly, then use of this activity should be one of our primary teaching tools.

At least two misperceptions have discouraged faculty members otherwise open to curriculum revision from integrating expressive writing into their classrooms. First, some instructors view with skepticism the supposed benefits of any nontraditional writing assignment, thinking that such an activity is designed to teach students how to write, a skill better learned in English or rhetoric courses. This fear confuses what has come to be termed writing across the curriculum (WAC), which is designed to improve quality of writing (Gere, 1985), with a subset of WAC, what has been called writing to learn (WTL), a method for encouraging focused thought and improved learning through the writing process. Expressive writing, as we have tested it in a horticultural context, places the emphasis upon focusing thought.

More widespread among faculty members, however, is the belief that informal writing cannot be integrated into a course without adding substantially to the instructor workload. Indeed, as the number and complexity of scientific details to be taught continues to mount, and as pressure to conduct and publish research increases, instructors employed by research institutions are highly unlikely to devote more time to conducting or grading student writing exercises. Berghage and Lownds (1991) addressed the is- 
sue of how to improve horticultural education in a climate of shrinking resources and proposed limiting the number of graded assignments and the time required to grade the assignments while increasing the quality of the assignments. Our study explores the use of WTL concepts in horticulture as a method for improving education without increasing workload.

In designing our study, the questions we asked were:

- Which types ofwriting tasks elicit the strongest/weakest student response, either within the context of the workbook entry or in classroom discussions?

-Which entry formats (formal writing, shorthand notes, illustrations, etc.) do students find most/least useful for continued reference?

- What guidelines do students require to get off to a quick start at the beginning of a course and, therefore, make best use of the writing experience?

- How does instructor behavior influence the level of student participation?

-What sort of reward/punishment grade system (if any) elicits greatest student participation?

-What type of post-task discussion structure is most/least productive for student and instructor alike?

- How can we best prepare instructors to use expressive writing throughout the horticulture curriculum?

- Can we integrate expressive writing into the horticulture curriculum without increasing faculty workload?

By integrating expressive writing tasks into two horticulture courses and recording observational data on the results, our study provides evidence for possible answers to these questions.

\section{Materials and methods}

We carried out our study in two courses:

1) Horticulture 1036 (Plant Propagation). This entry-level course is required of all horticulture students and has no prerequisites. The instructor had incorporated previously two writing requirements into the course, a set of lab reports and a short essay on any topic of interest to the student, which is printed subsequently as part of a weekly newsletter for the class to read. Both writing requirements are clearly transactional in nature.
2) Horticulture 5033 (Small Fruit Production). This upper-level undergraduate course requires a working knowledge of basic plant physiological and production concepts. Students traditionally have written one literature review and one group writing project focusing on production systems. Again, both assignments have required transactional writing.

All students enrolled in Horticuture 5033 and one of two sections of 1036 participated in a series ofwriting tasks designed to address material covered recently in class. (Because both sections of 1036 were taught by the same instructor and would therefore be unlikely to provide a valid comparison, we did not attempt to compare the two sections of the same course.) Task types fell into five general categories. These task types are:

1) The summary task, a restatement ofinformation presented in class, without further synthesis or integration of information, for example,

Based upon today s lecture, where would you site a small fruit operation? Why?

2) The compare and contrast task, the examination of two or more concepts (crops, practices, pathways, etc.) side-by-side. An example of this task type is, Explain to your uncle the differences and similarities that exist in the storage structures of his crocus, daffodil, and lily plants. Note that, by specifying the audience, the instructor can encourage students to consider vocabulary and tone-important in many horticultural employment fields.

3) The applied problem-solving task, the utilization of information presented in class to tackle a real-life situation. Example: A new nursery operator has a problem: After 3 weeks, none of the Abies concolor seeds he planted have germinated. What questions do you ask him? State your reason for asking each question.

4) The brainstorming task, the synthesis of new ideas based on recently presented information, or the integration of two or more areas of previously learned information into a new whole. A task that contains both summary and brainstorming elements is: What are the goals of a grape training system? Describe a system (existing or invented) that will help you reach those goals in the geographlcal region of your choosing.

5) The creative task, which differs from a brainstorming task mainly in tone; the creative task is more playful, more whimsical, and is designed to wake students from their complacency and provide a chance to relax while learning. An example of such a task is, Use an analogy to explain chromosomes to a group of fourth graders.

Of course, a degree of overlap exists between categories, and many of the tasks contain elements of more than one category. The tasks we designed during the course of our study were fairly evenly split between the various task types (Table 1), with a topic summary being a common starting point for many tasks of greater complexity.

At the conclusion of each class period during the quarter, we assigned students a short writing task of one of the types listed above. Students in 1036 took the task home, while those in 5033 were asked to spend $5 \mathrm{~min}$ writing before departure. At the beginning of the next class period, we instructed students to meet in groups of three to four for $5 \mathrm{~min}$ to share insights and to list any questions generated during their discussion. The class then reconvened as a whole for what we expected to be a questionand-answer session based on their group discussion.

\section{Methods of analysis}

We conducted a subjective analysis of both student writing and oral questions generated during the course of the quarter in the courses in which we used expressive writing. All questions asked during the question-andanswer class discussion were recorded

Table 1. Summary of task analysis for Hort 1036 and 5033 combined.

\begin{tabular}{lccc}
\hline Task type & $\begin{array}{c}\text { Frequency } \\
\text { used (\%) }\end{array}$ & $\begin{array}{c}\text { Student entries } \\
\text { rated engaged (\%) }\end{array}$ & $\begin{array}{c}\text { Discussions } \\
\text { rated engaged (\%) }\end{array}$ \\
\hline Summary & 30 & 80 & 83 \\
Compare/contrast & 13 & 68 & 100 \\
Problem solving & 23 & 79 & 83 \\
Brainstorming & 18 & 52 & 57 \\
Creative & 16 & 70 & 80 \\
\hline
\end{tabular}


and evaluated by the authors for complexity of thought, as demonstrated by the ability to analyze, manipulate, and integrate course information. Students collected and handed in their writing in the form of a workbook. All entries were evaluated for the same qualities as were questions raised during class discussions. For the purposes of generating numeric observational data, both class discussions and writing task entries were categorized by task type and rated as either engaging or not engaging the students. One or both authors attended both classes and recorded feedback from both students and instructors on a daily basis.

\section{Results and discussion}

Task types. Examination of writing task entries revealed that all question types elicited what we considered to be a significant level of engagement (Table 1). Our determination of engagement was entirely straightforward: Did the student make an effort to address coherently the topic of the task? The tasks requiring brainstorming yielded the lowest level of engagement-students, primarily those in 1036, expressed confusion or intimdation at tackling these often challenging tasks. For the same reason, brainstorming tasks yielded the lowest level of student engagement in question-and-answer sessions. All question types, however, sparked a dramatically improved level of participation and creative inquiry when compared to previous sections of both courses as well as the concurrent section of Plant Propagation. In fact, a few weeks into the quarter, the instructor of Plant Propagation became so concerned that students in the nonwriting section were asking so comparatively few questions that, convinced they were learning less, he began providing students in the nonwriting section expressive writing opportunities as well.

The success of all question types is somewhat surprising in light of student feedback received during each quarter. Some students complained that summary-type tasks bored them, leading us to combine summary elements with more-challenging types of questions. Similarly, although students complained about elements of whimsy found in the more creative tasks, leading us to believe participation would be low, we rated both workbook entries and class discussions involving creative tasks as evidencing significant levels of engagement. For example, in Hort 1036, a question asking for an analogy for chromosome structure inspired creativity and enthusiasm among many of the students. Many students proposed excellent analogies, and one student in particular came up with a particularly clever scheme (see sidebar).

Our conclusion, based on our evaluation of individual task entries and upon student feedback, is that students want tasks that they perceive as preparing them for a future exam. In addition, students need to know why they are asked to write. While our previous experience has been one where some students have resisted strongly nontraditional writing assignments, we found that, when introduced thoroughly to the philosophy behind expressive writing, students are more likely to accept writing tasks that they might otherwise view as a waste of time.

Entry format. Because students with a variety of approaches to the tasks reported an appreciation for the value of the tasks, we are convinced that any attention to expressive writing benefited the students in our courses, regardless of that approach. Students will benefit from expressive writing whether they favor a formal writing style, the jotting of shorthand notes, or the elaborate labeling of illustrations. A few students, however, made use of a particular format that enabled them to use their workbooks as a study guide for exams and, potentially, a future resource tool-one that involved both bulleted lists and visual representations of various concepts. Collected entries that contained an abundance of lists and drawings were more likely to contain later additions and changes. Such annotations extend the period of focused thought and, therefore, the learning process well beyond the initial lecture and writing period.

Even workbooks written in a more-formal style often contained annotations. The author of a conventionally written, yet highly annotated, workbook wrote us this note:

While studying I went though and made additional notes in pencil to myself or you. It has been a great use during studying by helping me focus on a larger move practical picture, to tie in ideas, especially in preparation for an essay test.
An example of student writing generated through expressive writing tasks

Tasks requiring creative thought frequently yielded surprising results. Witness this student's response to a question asking for an analogy of chromosomes understandable to a fourth-grade student.

Fourth graders-listen up. Genes are basic units of heredity. They control simple things like eye color and complicated things like height and weight. Living creatures get two sets of genes, one from their mother and one from theirfather. Genes are coded on strands called DNA. DNA is like a chain made up of four different kinds of links, like, if you made a paper chain using four different colors of paper. Three links in a row form a code that stands for something like a letter in a word. To understand this, assign a letter to each combination of three colors on your four-color chain. For example blueblue-blue $=A$, red-blue-blue $=B$, green-blue-blue $=\mathrm{C}$, and so on. There are 64 possible combinations, so you couldassign capitals, lowercase, punctuation, spaces, and paragraph marks. You could write a whole story on your paper chain.

A gene is like a paragraph in your story. DNA strands are very long, each carrying a thick-book's worth of information. However, all of the genetic information needed to make a human is like a set of encyclopedias. It would be too long, if all of this information was on one strand, so it is broken up into individual strands called chromosomes, like individual volumes in a set of encyclopedias. In your personal set of chromosomes (genetic encyclopedias), you have 24 pairs of volumes for a total of 48 volumes. One set of 24 came from your mother and one from your father. When your cells need to do something, they look up the right gene (paragraph) in the right chromosome (volume), and read the information. Sometimes they use one set of instructions over the other If one set says brown eyes and the other says blue, your cells will go with the brown-eye instructions. Sometimes they will kind of follow both-if one volume says kinky hair and the other volume says straight, you may get wavy hair. 
Such feedback reinforces our understanding that, when students write, material covered in lecture is reinforced and put into terms with which they are most comfortable; when they return to that entry to make revisions, the learning process continues much longer than if they were to rely only upon lecture notes, which are quickly put aside and forgotten. The value of such an extended learning process cannot be underestimated.

End-of-term written evaluations substantiated the positive feedback concerning the contribution of writing to learning that we received as each term progressed. Although no evaluation question asked for feedback on the writing tasks specifically, comments included the following:

The writing aspects are a good part of the course-make you think about the topic.

I appreciate the way we were required to analyze a topic though essay exams and [task] writing. I really feel I ve got a grasp of the topic and know what further questions should be asked on other similar subjects.

Workbook with daily questionsexcellent! Promotes wide-ranging thinking- and grasp of broad issues. Wish for more time for discussions on most questions.

We find such feedback exciting; after all, how often are students enthusiastic about being asked to write?

Student guidelines. We have found that students require extensive guidelines at the beginning of a course in which workbooks are used because previous educational experience has not likely prepared them for such a learning tool. Because expressive writing as a learning tool is new for our students, we agree with Berghage (1991), who suggested that instructors must know the purpose of each writing task and must make it clear to their students why and how each task should be attempted. In both courses, we felt it necessary a few weeks into each quarter to restate the philosophy and goals behind expressive writing to reassure students of the value of the writing tasks. We learned quickly, however, that a midquarter exam that reflects task format and content does more to motivate than all the reassurance in the world. We recommend that student guidelines should include the following information:

- An explanation of expressive writing as nonformal and self-audienced.

-Further explanation that the writing process itself, not the concrete outcome, is most important to learning.

-A description of most-useful format ideas, including bulleted lists and drawings.

- Descriptions and examples of the types of tasks they may expect.

- Explicit reassurance that spelling, punctuation, organization, or factual accuracy will not be graded. Legibility and attention to the assigned topic are the only requirements.

Because students have been taught to listen carefully to the internal censor, students may benefit from reminders that the process is more important than the product as the quarter progresses.

Instructor behavior. Our experience has led us to conclude that instructors must back up their words with acts that indicate commitment to the tasks. This involves:

-Writing with the class if in-class writing occurs. One instructor discovered early in the quarter that this simple act resulted in significantly improved student effort. Writing with the class validates the importance of writing, and says, I care enough about learning to want to do it, too. Set an example.

- Keeping small discussion groups, if used, on-task. This includes remaining in the classroom during smallgroup discussion, refusing to answer questions unrelated to the task at hand, and perhaps circulating-not to intrude on discussions, but to facilitate if necessary. As with in-class writing, we observed that students focused better when the instructor set an example. Again, such behavior stresses a belief in the importance of the process.

- Opening channels of communication. We confirmed the importance of eliciting student responses to the tasks and making flexibility in future tasks clear. Our first task assignment was, Describe your expectations for this course. We then made it clear that we responded promptly to feedback by listening to students course expectations and negotiating changes if the suggestions were reasonable. The positive student response was such that we recommend using this question the first day of each term. As a term progresses, if the response to a task makes it obvious the material is not understood, then the instructor must be willing to respond in kind, and try again. Students want their despots to be enlightened.

Spend the effort to write good questions. Students could smell what they perceived to be a lazy question a mile away, and responded with diminished effort. Make tasks challenging, but fair. We found that they should be clearly designed to prepare the student for exams, employment situations, or life.

Motivation/time requirement. In both courses, turning in collected writings at the end of the quarter was an extra-credit option; both instructors were known as providing numerous opportunities to earn a high grade. If an $\mathrm{A}$ is likely anyway, does this diminish motivation? Furthermore, in a larger entry-level class such as Hort 1036, which potentially includes some poorly motivated students taking the course only because it is required, can we motivate students no matter the reward? Based on our experience, primarily in Hort 1036, we propose that workbooks that contain collected entries should be required and be graded on a pass-fail basis only. Because we propose further that workbooks be evaluated only for participation at the end of the quarter, the time required is minimal; it takes very little time to verify that a given student has completed a given percentage of assignments and complied with legibility and topic attention requirements. Coupled with the fact that the workbook can replace easily another writing requirement within the course, the time spent grading during the term should actually decrease-an attractive situation for most instructors.

Discussion. What we had anticipated would be basic question-andanswer sessions proved quickly to be much more-we discovered that wellthought-out tasks have the potential to spark amazing class discussions. Certain tasks, especially in plant propagation, resulted in lively, spirited, and far-reaching sessions in which students built questions upon questions and even took some of the responsibility for answering them as well. This freeflowing creativity may intimidate some instructors who require more formal control. In addition, these discussions may require extra class time. As we fell 
behind the lecture schedule in one course over several weeks, the instructor responded by restricting discussions. The instructor tended to answer the question posed by one small group, then, rather than allow a natural follow-up question, moved to another small group to elicit other questions on the topic at hand. This squelched effectively any natural progression of inquiry and kept questions at a moresimplistic level. Can we convince instructors to relinquish some control and perhaps find they can cover less material? Fulwiler (1987) suggests that educational approaches that enable students to synthesize material for themselves increase the value of the material covered. Chances are that students actually perform better in the long run if they are exposed to fewer topics, but are exposed to them in greater depth through the process of thinking, writing, and discussion.

Instructor guidelines. The idea ofinstructor control leads rather naturally to the concept ofinstructor guidelines. What do we need to tell instructors? Clearly, we are not talking only about integratingwriting into the classroom; we are talking about a wholesale renovation of teaching methods. The system we have studied in 5033 and 1036, one involving both expressive writing and group discussion, has at least one unintended consequence: instant student feedback. The instructor finds out at discussion time how well the topic at hand has been taught/ learned-information that requires confidence, flexibility, and a good dose of humility.

Instructors clearly have to be prepared and motivated as thoroughly as students, using the information listed above. We believe that, by encouraging instructors to examine the goals of horticultural education, we may find our best motivational tool. Deep down, most instructors want to teach well with their limited resources. We intend to keep this basic truth in mind as we pursue continued improvement in horticultural education.

\section{Literature Cited}

Bemiller, S. 1987. The mathematics workbook, p. 359-366. In: T. Fulwiler (ed.). The journal book. Boynton/Cook, Portsmouth, N.H.
Berghage, R.D. and N.K. Lownds. 1991. Using writing in horticultural education. HortTechnology 1(1):124-126.

Couch, R. 1991. Five minutes to monitor progress. The Teaching Professor 5(9):1-2.

Fulwiler, T. 1986. The argument for writing across the curriculum, p. 21-32 In: Young and Fulwiler (eds.). Writing across the disciplines: Research into practice. Boynton/Cook, Portsmouth, N.H.

Fulwiler, T. 1987. Teaching with writing. Boynton/Cook, Portsmouth, N.H.

Gere, A. Ruggles (ed.). 1985 Roots in the sawdust: Writing to learn across the disciplines. Natl. Council of Teachers of English.

Goldbeg, N. 1986. Writingdown the bones: Freeing the writer within. Shambhala, Boston.

Johnson, D.W., R.T. Johnson, and K.A. Smith. 1991. College teaching and cooperative learning. Active learning: Cooperation in the college classroom. Interaction, Edina, Minn. p.1-27.

Knoblauch, C.H. and L. Brannon. 1983. Writing as learning through the curriculum. College English 45(5):465-474. 